\title{
Characterization of Antibacterial Activity and Potential as Probiotic of Lactic Acid Bacteria Isolated from Goat's Milk in Algeria
}

\author{
Mokhtar Benreguieg ${ }^{1,2,3}$, Fatiha Dalache ${ }^{3,4}$ and Bouabdelah Gacemi ${ }^{1,2}$ \\ 1. Departement of Biology, University Tahar Moulay, Saida 20000, Algeria \\ 2. Laboratory of Sciences and Techniques of Animal's Production, Mostaganem 27000, Algeria \\ 3. Departement of Biology, University Abdelhamid Ibn Badis, Mostaganem 27000, Algeria \\ 4. Laboratory of Microorganisms’ Biology and Biotechnology, Es-senia University, Oran 31000, Algeria
}

Received: June 01, 2013 / Accepted: August 01, 2013 / Published: August 30, 2013.

\begin{abstract}
Lactic acid bacteria (LAB) were isolated from goat's milk in different north west region of Algeria. A total of 233 isolates were identified as LAB. However, only 11 strains showed excellent inhibition zones on agar when Salmonella typhimorium ATCC 13311 was used as an indicator for preliminary detection of antagonistic activity. After elimination of inhibition due to acid and $\mathrm{H}_{2} \mathrm{O}_{2}$, Staphylococcus aureus ATCC 25923 was used for secondary screening for antagonistic activity of these 11 strains. It was found that only 9 strains exhibited a good inhibition zones on agar, and all of them could inhibit E. coli ATCC 25921 and Pseudomonas aeruginosa ATCC 27853 as the third and the forth indicators respectively. Lactococcus lactis subsp. cremoris, Lactobacillus casei subsp. casei, Lactobacillus casei subsp. rhamnosus, Streptococcus salivarius subsp. thermophilus and Lactococcus lactis biovar. diacetylactis were the strains that have a good antibacterial activity, survive in the gastrointestinal conditions and were sensible to the majority of the antibiotics. All isolated strains tolerate $\mathrm{pH}=2$ and high bile salt concentration.
\end{abstract}

Key words: Goat's milk, lactic acid bacteria, antibacterial activity.

\section{Introduction}

In Algeria, the goat population is very high (17\%), second only to sheep (28\%) [1]. The caprine livestock is concentrated in the mountainous and arid areas. These goats are very adaptable to the climatic conditions and ensure the production of meat, milk and skins. Goat milk plays a vital role in human consumption, most being consumed by the rural community, while little is available on the market. Characterization and identification of the microflora from goat's milk was analyzed in different countries, like Spain [2-5], Bulgaria [6] and Algeria [7].

Lactic acid bacteria (LAB) can produce antimicrobial substances with the capacity to inhibit

Corresponding author: Mokhtar Benreguieg, Ph.D., research field: microbiology. E-mail: mokhtar_benreguieg@yahoo.com. the growth of pathogenic and spoilage micro-organisms. Organic acids, hydrogen peroxide, diacetyl and bacteriocins are included among these compounds [8]. Interest in naturally produced antimicrobial agents, such as bacteriocins, is on the rise, since nowadays consumers demand "natural" and "minimally processed" food [9].

The goal of probiotic therapy is to increase the number and activities of microorganisms that presumably possess health promoting properties and re-establish the normal flora $[10,11]$. Commonly used bacterial probiotics include various species of Lactobacillus, Bifidobacterium and Streptococcus, as well as Lactococcuslactis and some Enterococcus species. Currently, the only probiotic yeast used is the nonpathogenic Saccharomyces boulardii [12]. 
The aim of this work was, firstly, to isolate and to identify the lactic acid bacteria from Algerian goat milk. Isolates were characterized in terms of their antimicrobial activity and certain in vitro of characteristics related to the probiotic potential.

\section{Material and Methods}

\subsection{Sampling}

A total of 28 samples of goats' milk were collected from different regions in the north west of Algeria. Samples were immediately cooled and transported to the laboratory in an icebox $\left(4{ }^{\circ} \mathrm{C}\right)$ and analyzed for content of LAB the arrival.

\subsection{Isolation and Enumeration of Lactic Acid Bacteria}

Ten (10) $\mathrm{mL}$ of milk sample were homogenized with $90 \mathrm{~mL}$ of sterile solution containing $0.1 \%(\mathrm{w} / \mathrm{v})$ peptone (Biokar, France) and $0.85 \%(\mathrm{w} / \mathrm{v}) \mathrm{NaCl}$ (Prochima, Algeria). Ten-fold serial dilutions of the meat homogenate were prepared in peptone water to spread the sample on de Man Rogosa Sharpe agar (MRS, Biokar Diagnostics, France) with $1 \mathrm{~g} / \mathrm{L}$ of sorbic acid (Sigma-aldrich, USA) to inhibit yeast and molds growth. After incubation for $72 \mathrm{~h}$ at $30{ }^{\circ} \mathrm{C}, 10$ colonies were randomly picked from each plate. Attention was given to choose colonies with different macroscopic morphology. Isolates were inoculated in MRS broth, incubated at $30^{\circ} \mathrm{C}$ and checked for purity by streaking on MRS agar. Plates with pure cultures were used to test for cell morphology by phase contrast microscopy, Gram stain and catalase formation. Gram positive and catalase negative strains were selected. These isolates were maintained as frozen stocks in MRS broth supplemented with $10 \%(\mathrm{v} / \mathrm{v})$ glycerol at $-20{ }^{\circ} \mathrm{C}$ during a month. Before experimental use, all LAB strains were recovered in MRS broth and were incubated at $30^{\circ} \mathrm{C}$ for $24 \mathrm{~h}$.

\subsection{Detection of Antagonistic Activity}

The agar spot test was used for detection of antagonistic activity as described by Schillinger and
Lucke [13]. Approximately $10^{4} \mathrm{CFU} / \mathrm{mL}$ of the strains to be tested for production of an antimicrobial compound were spotted onto the surface of MRS agar plates $\left(1.5 \%\right.$ agar) and incubated for $48 \mathrm{~h}$ at $37{ }^{\circ} \mathrm{C}$ to allow development of colonies. The plates were overlaid with $10 \mathrm{~mL}$ of nutrient soft agar $(0.75 \%$ agar). The overlay agar was seeded with $10^{4} \mathrm{CFU} / \mathrm{mL}$ of the pathogenic bacteria to be tested for sensitivity (Escherichia coli, Pseudomonas aeruginosa, Staphylococcus aureus and Salmonella Typhimirium). After incubation for $24 \mathrm{~h}$ at $37{ }^{\circ} \mathrm{C}$ the plates were checked for inhibition zone diameters. Inhibition was scored as positive if the width of the clear zone around the colonies of the producer strain was $10 \mathrm{~mm}$ of larger.

Strains exhibiting antagonistic activities against pathogenic bacteria were investigated for their antimicrobial compounds as described by Aslim et al. [14]. Strains of LAB were grown for $24 \mathrm{~h}$ at $37^{\circ} \mathrm{C}$ in $10 \mathrm{~mL}$ of MRS broth and then centrifuged at $9500 \mathrm{~g}$ for $10 \mathrm{~min}$. Three samples of the supernatant were taken from each strain of LAB.

Samples 1 and 2 were adjusted to $\mathrm{pH} 6.5$ with $\mathrm{NaOH}(1 \mathrm{~N})$ to avoid acid inhibition. For sample 2, a catalase solution (Fluka, Germany) (300 U/mL in PBS buffer, $\mathrm{pH}=7$ ) was added in order to remove the inhibitory effect of hydrogen peroxide. For sample 3, the supernatant was used as a control. The antagonistic activity of the three samples was detected using the well diffusion agar method [15]. $20 \mathrm{~mL}$ of soft BHI agar (containing 1.0\% agar) were poured on sterile plates and inoculated with an overnight culture of pathogenic bacteria (about $10^{7} \mathrm{CFU} / \mathrm{mL}$ ). After solidification, wells were perforated using a sterile cork borer (7.0 mm diameter). The culture filtrates (50 $\mu \mathrm{L})$ were placed in each well. The plates were incubated at $37{ }^{\circ} \mathrm{C}$ and examined after $24 \mathrm{~h}$ for clear zones showing the pathogenic bacteria inhibition. The diameters of the inhibition zones were measured and the diameter of the well, $7 \mathrm{~mm}$, was subtracted from the total zone diameter. 


\subsection{Characterization of Isolates}

LAB strains were characterized according to the methods recommended by several authors [16-23]. All strains were initially subjected to Grams training, catalase test, growth at $10{ }^{\circ} \mathrm{C}$ and $45^{\circ} \mathrm{C}$ in MRS and M17 broth, gas production from glucose and growth in the presence $6.5 \%$ of $\mathrm{NaCl}$. Only, the strains that exhibiting antagonistic activities against pathogenic bacteria were identified by the API 50CHL identification kit (Biomerieux).

\subsection{Sensitivity to Heat and Proteolytic Enzymes}

Sensitivity to heat of the antibacterial compounds was investigated by treating the culture supernatants in water bath at $80{ }^{\circ} \mathrm{C}$ for $10 \mathrm{~min}$ and for $2 \mathrm{~h}$. After heat treatment, samples were cooled to $4{ }^{\circ} \mathrm{C}$ and the residual activity was determined by the AWDA as described above. Sensitivity to proteolytic enzymes of the antibacterial compounds was investigated by the addition of Trypsin T-4799 and Proteinase K P-5056 (Sigma-Aldrich Chemie) at final concentration of $1 \mathrm{mg} \cdot \mathrm{mL}^{-1}$ to the culture supernatants. The samples were incubated for $3 \mathrm{~h}$ at $37{ }^{\circ} \mathrm{C}$ and the residual antibacterial activity was immediately determined by the AWDA as described above.

\subsection{Determination of $L A B$ Growth for Maximum Bacteriocin Production}

The incubation time at which the selected LAB strain exhibited a maximum bacteriocin production was determined as follows: sterile flasks containing 50 $\mathrm{mL}$ of MRS broth were inoculated with $1 \%(\mathrm{v} / \mathrm{v})$ of bacteriocin-producing $\mathrm{LAB}$ strain and incubated at $30{ }^{\circ} \mathrm{C}$. Then, $1 \mathrm{~mL}$ of aliquots was retrieved after 0 , $1.5,3,4.5,6,9,12,15,24$ and $36 \mathrm{~h}$ in order to monitor the production of bacteriocin along the bacterial growth. Bacteriocin production was determined by the well diffusion agar method. The diameters of inhibition zone were measured after incubation $24 \mathrm{~h}$ at $37^{\circ} \mathrm{C}$ [24].
2.7 Survival Tests under Conditions Simulating the Human GI Tract

\subsubsection{Resistance to Low $\mathrm{pH}$}

The methods used and described below are according to Maragkoudakis et al. [25] and Zoumpopoulou et al. [26]. Bacterial cells from overnight $(18 \mathrm{~h})$ cultures were harvested $(10,000 \times \mathrm{g}$, 5 min, $\left.4{ }^{\circ} \mathrm{C}\right)$, washed twice with PBS buffer $(\mathrm{pH}=$ 7.2), before being re-suspended in PBS solution, adjusted to $\mathrm{pH}=2.5$. Resistance was assessed in triplicates in terms of viable colony counts and enumerated on MRS agar (BK089HA, Biokar Diagnostics) after incubation at $37^{\circ} \mathrm{C}$ for $0,0.5,1,2$, and $3 \mathrm{~h}$, reflecting the time spent by food in the stomach.

\subsubsection{Resistance to Bile Salts}

Bacterial cells from overnight $(18 \mathrm{~h})$ cultures were harvested $\left(10,000 \times \mathrm{g}, 5 \mathrm{~min}, 4{ }^{\circ} \mathrm{C}\right)$ and washed twice with PBS buffer ( $\mathrm{pH} 7.2)$, before being re-suspended in PBS solution (pH8.0) containing $0.5 \%(\mathrm{w} / \mathrm{v})$ bile salts (LP0055, Oxoid). Resistance was assessed in triplicatesin terms of viable colony counts and enumerated after incubation at $37^{\circ} \mathrm{C}$ for $0,1,2$ and $4 \mathrm{~h}$ reflecting the time spent by food in the small intestine.

\subsubsection{Bile Salts Hydrolysis}

Fresh bacterial cultures were streaked in triplicates on MRS agar containing $0.5 \%(\mathrm{w} / \mathrm{v})$ taurodeoxycholic acid (T0875, Sigma). The hydrolysis effect was indicated by different colony morphology (partial hydrolysis) from the control MRS plates, after $48 \mathrm{~h}$ of anaerobic incubation at $37^{\circ} \mathrm{C}$.

\subsection{Statistical Analysis}

Statistical analysis was performed using one-way ANOVA with post hoc Duncan's test; $P<0.05$ was considered significant. All data are expressed as mean $\pm \mathrm{SD}$.

\section{Results and Discussion}

\subsection{Isolation of Lactic Acid Bacteria}

Different types of colonies developed on the surface 
of MRS agar plate after 1 day of incubation at $37^{\circ} \mathrm{C}$, and after 48 or $72 \mathrm{~h}$. A total of 320 strains were purely isolated and showed biochemical characteristic of lactic acid bacteria: small, round, opaque and white colonies, non-sporulated, Gram-positive, non-motile cells, catalase negative. Twenty-six strains were chosen on the basis of their antimicrobial activity relative to five reference strains.

\subsection{Detection of Antagonist Activity}

The antibacterial activity of $46 \mathrm{LAB}$ isolates toward Salmonella Typhimirium was firstly determined by an agar spot test. However, only 9 strains showed excellent inhibition zones diameters larger than 40 $\mathrm{mm}$, as shown in Table 1. Strain LCM07 produced the widest inhibition zone diameter on agar. The 9 LAB strains were then secondary screened for St. aureus, $L$. monocytogenes, $P$. aeruginosa and $E$. coli inhibition by the agar spot test. The antagonistic effects of the LAB are presented in Table 1.

Only two strains (LCS11 and LCB17) of the isolates showed low antimicrobial activity against Listeria monocytogenes (inhibition zones diameters < $10 \mathrm{~mm})$. However, all nine isolates showed antimicrobial activity against St. aureus and at least one of indicator microorganisms.

It was found that antagonistic activities to ward St. aureus of all 9 LAB strains were lower than this capability against $S$. typhimirium.
St. aureus is Gram-positive bacteria which have a thick mesh-like cell wall made of peptidoglycan $(50 \%$ to $90 \%$ of cell wall), while $S$. typhimirium is Gram-negative bacteria with a thinner layer (10\% of cell wall). Gram-negative bacteria also have an additional outer membrane which contains lipids, and is separated from the cell wall by the periplasmic space. The antibacterial action of lactic acid is largely, but not totally, assigned to its ability in the undissociated form to penetrate the cytoplasmic membrane. This results in reduced intracellular $\mathrm{pH}$ and disruption of the transmembrane proton motive force [27]. The relative efficacy of lactic acid against Gram-negative bacteria is not unexpected. This is because the small water-soluble molecule lactic acid gains access to the periplasm through the water-filled porin proteins of the OM (outer membrane), as reviewed by Nikaido [28].

The OM, however, functions as an efficient permeability barrier that is able to exclude macromolecules (such as bacteriocins or enzymes) and hydrophobic substances (such as hydrophobic antibiotics). The permeability barrier property of the OM is largely due to the presence of a specific LPS (lipopolysaccharide) layer on the membrane surface. LPS molecules consist of a lipid part, termed lipid A, and a hydrophilic heteropolysaccharide chain protruding outward and providing the cell with a hydrophilic surface [29].

Table 1 Inhibition zone diameters of LAB isolated from goats' milk on agar when S. typhimirium, St. aureus, P. aeruginosae and $E$. coli were used as indicator.

\begin{tabular}{lllll}
\hline \multirow{2}{*}{ Isolated No. } & \multicolumn{3}{c}{ Inhibition zone $(\mathrm{mm})$} \\
\cline { 2 - 5 } & S. typhimirium & St. aureus & P. aeruginosa & E. coli \\
\hline LCS01 & $44.2 \pm 8.3^{*}$ & $42.3 \pm 2.1$ & $31.6 \pm 5.2$ & ND \\
LCM03 & $41.7 \pm 4.2$ & $19.6 \pm 1.8$ & $29.7 \pm 7.3$ & $33.6 \pm 6.4$ \\
LCM05 & $45.1 \pm 5.2$ & $31.4 \pm 7.6$ & $\mathrm{ND}$ & ND \\
LCM07 & $47.3 \pm 6.6$ & $45.6 \pm 2.4$ & $25.2 \pm 6.4$ & $42.6 \pm 7.8$ \\
LCS11 & $51.2 \pm 8.1$ & $41.5 \pm 7.5$ & $\mathrm{ND}$ & $24.5 \pm 3.2$ \\
LCS13 & $42.8 \pm 2.1$ & $33.7 \pm 2.7$ & $\mathrm{ND}$ & $27.5 \pm 5.8$ \\
LCS15 & $44.3 \pm 5.0$ & $21.3 \pm 3.2$ & $27.3 \pm 7.7$ & $18.3 \pm 6.7$ \\
LCB17 & $46.6 \pm 3.3$ & $44.5 \pm 4.3$ & $18.6 \pm 6.3$ & ND \\
LCB26 & $45.0 \pm 3.9$ & $43.1 \pm 5.2$ & $\mathrm{ND}$ & $41.1 \pm 4.4$ \\
\hline
\end{tabular}

${ }^{*}$ Mean \pm SD from triplicate determinations. ND: not determinated. 
In the present study, it was found that LCM07, LCB17 and LCB26 produced the widest inhibition zones when St. aureus was used as an indicator. In addition, for a third screening against E. coli and inhibition, only 2 strains exhibited inhibition zones on agar, as shown in Table 1. The strains which showed the widest zones of inhibition against $E$. coli were LCM07 and LCB26.

The widest inhibition zone was produced by LCS01 when P. aeruginosa was used. Roth and Keenan [30] reported that lactic acid is able to cause sub-lethal injury to E. coli, and similar properties have also been assigned to acetic acid [31]. Indirect evidence suggests that such injury involves disruption of the LPS layer. A permeabilizer function of lactic acid would not only be utilizable in decontamination procedures and in protective cultures. It would also provide a mechanistic explanation for the antimicrobial and health-promoting effects of probiotic lactic acid bacteria [32].

Lactic acid, in addition to its antimicrobial property due to the lowering of the $\mathrm{pH}$, also functions as a permeabilizer of the Gram negative bacterial outer membrane. It may also act as a potentiator of the effects of other antimicrobial substances [33].

Three LAB strains (LCS1, LCM05 and LCB26) which exhibited inhibitory efficiency toward tested pathogenic bacteria were analyzed for their production of antibacterial compounds. Supernatants obtained from all strains did not exhibit the inhibition zones after $\mathrm{pH}$ adjustment to 6.5. It indicated that the inhibitory effect toward pathogenic bacteria mainly because of organic acid. LAB produces various compounds such as organic acids, diacetyl, hydrogen peroxide, and bacteriocin or bactericidal proteins during lactic fermentations. The bacteriocins from them are generally recognized as safe (GRAS) and LAB have attracted a great deal of attention as a novel approach to control pathogens in food-stuffs [34]. Levels and types of organic acids produced during the fermentation process depend on LAB species or strains, culture composition and growth conditions [35]. Hydrogen peroxide is produced by LAB in the presence of oxygen as a result of the action of flavoprotein oxidases or NADH (nicotinamide adenine dinucleotide) peroxidase. The antimicrobial effect of hydrogen peroxide may result from the oxidation of sulfhydryl groups causing denaturing of a number of enzymes, and from the peroxidation of membrane lipids thus increasing membrane permeability [36, 37].

The antimicrobial effect of organic acids lies in the reduction of $\mathrm{pH}$, as well as the undissociated form of the molecules. It has been proposed that the low external $\mathrm{pH}$ causes acidification of the cell cytoplasm, while the undissociated acid, being lipophilic, can diffuse passively across the membrane. The undissociated acid acts by collapsing the electrochemical proton gradient, or by altering the cell membrane permeability which results in disruption of substrate transport systems [38].

\subsection{Identification of Selected Strains}

The nine strains which exhibited widest zones of inhibition were identified as Streptococcus salivarius subsp. thermophilus (LCS01), Leuconostoc lactis (LCM03 and LCS13), Lactococcus lactis subsp. lactis (LCM05), Lactococcus lactis subsp. cremoris (LCM07), Lactococcus lactis biovar. diacetylactis (LCS11 and LCS15), Lactobacillus casei subsp. casei (LCB17) and Lactobacillus casei subsp. rhamnosus (LCB26), as shown in Table 2.

\subsection{Effect of Heat and Proteolytic Treatments on Antibacterial Activity}

Application of Trypsin T-4799 and Proteinase KP-5056 (Sigma-Aldrich Chemie) at final concentration of $1 \mathrm{mg} \cdot \mathrm{mL}^{-1}$ led to inactivation of the antagonistic activities of culture supernatants. Heating at $80{ }^{\circ} \mathrm{C}$ for $10 \mathrm{~min}$ did not affect the antibacterial compounds since the AWDA showed residual activities of samples. However, no inhibition zones 
Table 2 Carbohydrates fermentation of lactic acid bacteria isolated from raw goats' milk.

\begin{tabular}{llllllllllllllllllllll}
\hline Species Star & Amy & Ara & Cel & Fru & Gal & Glu & Lac & Mal & Man & Mos & Mel & Mlz & Raf & Rha & Rib & Suc & Sal & Sor & Tre & Xyl \\
\hline LCS01 - & - & - & - & - & + & + & + & - & - & - & - & - & $\mathrm{v}$ & - & - & + & - & - & - & - \\
LCM03 - & - & - & - & + & + & + & + & + & - & $\mathrm{v}$ & - & $\mathrm{v}$ & $\mathrm{v}$ & - & - & - & - & - & - & - \\
LCM05 + & - & - & + & + & + & + & + & + & - & + & - & - & - & - & + & - & + & - & $\mathrm{v}$ & $\mathrm{v}$ \\
LCM07 & - & - & + & + & + & + & + & - & - & + & - & - & - & - & - & - & - & - & - & $\mathrm{v}$ \\
LCS11 - & - & - & - & + & + & + & + & + & - & + & - & - & & - & + & + & - & + & - & + \\
LCS13 - & - & - & - & + & + & + & + & + & - & $\mathrm{v}$ & - & $\mathrm{v}$ & $\mathrm{v}$ & - & - & - & - & - & - & - \\
LCS15 - & - & - & - & + & + & + & + & + & - & + & - & - & & - & + & + & - & + & - & + \\
LCB17 - & + & - & + & + & + & + & - & $\mathrm{v}$ & + & + & + & $\mathrm{v}$ & - & - & - & - & + & - & + & - \\
LCB26 - & + & - & + & + & + & + & + & + & + & + & + & - & - & + & + & - & + & + & + & - \\
\hline
\end{tabular}

+: Positive reaction; -: Negative reaction; v: variable.

LCS01: Streptococcus salivarius subsp. thermophilus; LCM03: Leuconostoc lactis; LCM05: Lactococcus lactis subsp. lactis; LCM07: Lactococcus lactis subsp. cremoris; LCS11: Lactococcus lactis biovar. diacetylactis; LCS13: Leuconostoc lactis; LCS15: Lactococcus lactis biovar. diacetylactis; LCB17: Lactobacillus casei subsp. casei; LCB26: Lactobacillus casei subsp. rhamnosus.

Star: Starch; Amy: Amygladin; Mlz: Melizitose; Sor: Sorbitol; Tre: Trealose; Ara: Arabinose; Raf: Raffinose; Xyl: Xylose; Rib: Ribose; Suc: Sucrose; Rha: Rhamnose; Cel: Cellubiose; Mel: Melibiose; Sal: Salicin; Man: Mannitol; Mos: Mannose; Fru: Fructose; Gal: Galactose; Glu: Glucose; Lac: Lactose; Mal: Maltose.
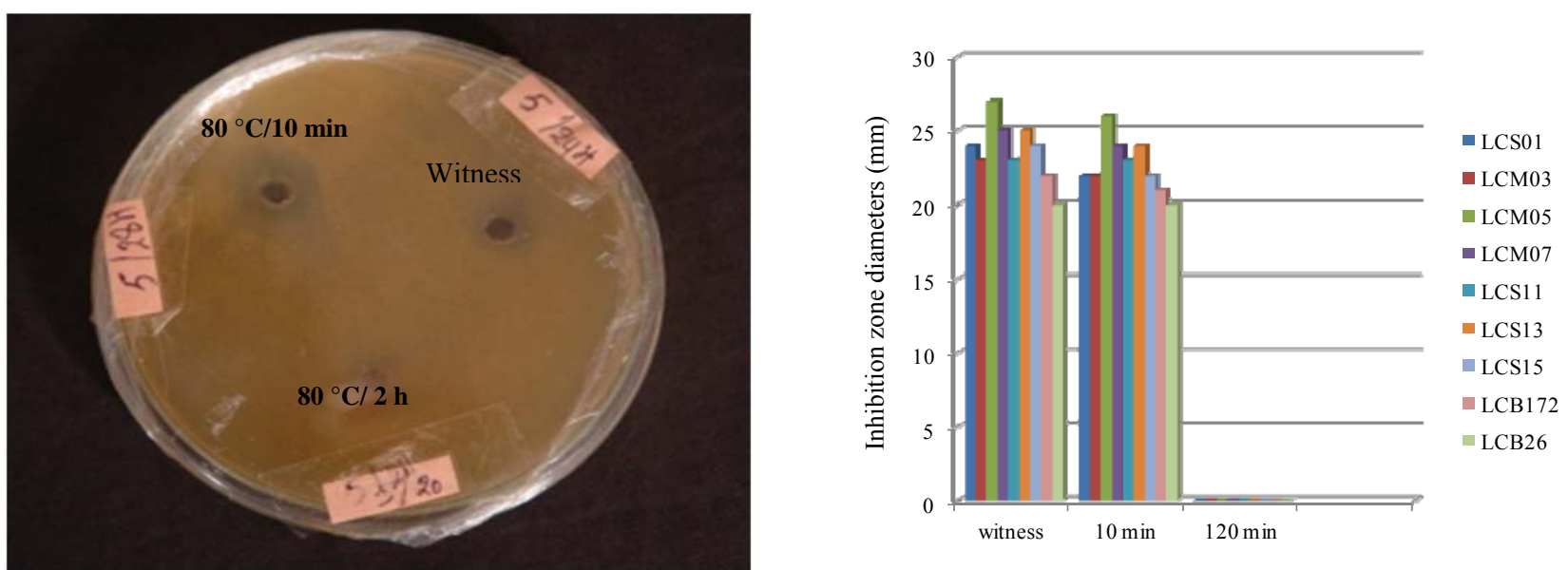

Fig. 1 Inhibition zones after heating treatment (LCS01: Streptococcus salivarius subsp. thermophilus; LCM03: Leuconostoc lactis; LCM05: Lactococcus lactis subsp. lactis; LCM07: Lactococcus lactis subsp. cremoris; LCS11: Lactococcus lactis biovar. diacetylactis; LCS13: Leuconostoc lactis; LCS15: Lactococcus lactis biovar. diacetylactis; LCB17: Lactobacillus casei subsp. casei; LCB26: Lactobacillus casei subsp. rhamnosus).

were observed after heating at $80{ }^{\circ} \mathrm{C}$ for $2 \mathrm{~h}$, as shown in Fig. 1.

Antibacterial activity could be detected only on agar plated in overlay assays, and was unsuccessfully researched in cell-free culture supernatant fluids under conditions that eliminate acid and hydrogen peroxide inhibition.

Therefore regarding the proteinaceous nature, the thermostability at $80{ }^{\circ} \mathrm{C}$ for $10 \mathrm{~min}$ of antibacterial compounds and their residual activities after ruling out acid and hydrogen peroxide inhibition, it was concluded that theses antibacterial compounds were bacteriocin-like [39]. It must also be kept in mind that the production and extraction of bacteriocins may be affected by a range of factors. Among these it is possible to cite the composition of the culture medium, including carbon, nitrogen and sources of phosphates, cations, surfactant and inhibiting agents, the optimum $\mathrm{pH}$, aeration and growth temperature [40-43]. Generally, for the maximum production of bacteriocins it is necessary to have a complex medium whose $\mathrm{pH}$ does not usually coincide with the optimum 
$\mathrm{pH}$ for bacteriocin action [41]. In addition, further factors may have an influence, such as the adsorption of bacteriocins on the cell wall of the producing micro-organisms. This effect may well be the prime mechanism causing a decline in bacteriocin activity, followed by hydrolysis of proteins $[42,44]$.

\subsection{Determination of $L A B$ Growth for Maximum Antibacterial Agent Production}

Maximum inhibitory activity against St. aureus was found at $24 \mathrm{~h}$ of incubation at $30{ }^{\circ} \mathrm{C}$, which corresponded to the stationary phase, as shown in Fig. 2. Likewise, maximum inhibitory activity of all strains against St. aureus was detected after $15 \mathrm{~h}$ of incubation, coinciding with the beginning of the stationary phase of growth in Fig. 2. In both cases, after time mentioned no further increase of inhibitory activity was found. Moreover, a decrease of $50 \%$ in the antimicrobial activity of the bacteriocin-producing strain LCB17 and LCB26 against St. aureus was observed at $36 \mathrm{~h}$ of incubation.

A number of factors must be taken into consideration when choosing a bacteriocinogenic strain for bacteriocin in situ or ex situ production. Among several factors, presence and concentration of food additives are master keys for an optimum performance of a bacteriocinogenic strain in a producing medium and especially for lacto bacilli strains, the decrease in $\mathrm{pH}$ of the medium has a significant effect on the production of bacteriocin [45]. Hence, the quantity of the response may be specific for the combinations of bacteriocins, food additives and target organisms.

\subsection{Survival under Conditions Simulating the Human GI Tract}

In order to act as a probiotic in the gastrointestinal tract and to exert their beneficial effect on the host, the bacteria must be able to survive the acidic conditions in the stomach and resist bile acids at the beginning of the small intestine [46, 47].

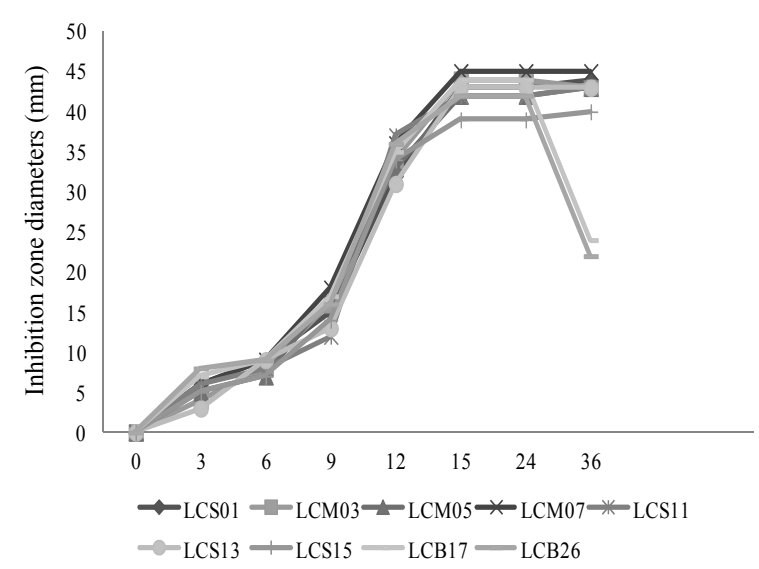

Fig. 2 LAB growth for maximum antibacterial agent production (LCS01: Streptococcus salivarius subsp. thermophilus; LCM03: Leuconostoc lactis; LCM05: Lactococcus lactis subsp. lactis; LCM07: Lactococcus lactis subsp. cremoris; LCS11: Lactococcus lactis biovar. diacetylactis; LCS13: Leuconostoc lactis; LCS15: Lactococcus lactis biovar. diacetylactis; LCB17: Lactobacillus casei subsp. casei; LCB26: Lactobacillus casei subsp. rhamnosus).

Approximately $2.5 \mathrm{~L}$ of gastric juice [48] and $1 \mathrm{~L}$ of bile [49] are secreted into the human digestive tract every day. Thus, it is essential for the bacteria to have protection systems to withstand the low $\mathrm{pH}$ in the stomach, digestive enzymes and bile in the small intestine.

\subsubsection{Resistance Ability to Low $\mathrm{pH}$}

The nine strains of LAB showed higher resistance to low $\mathrm{pH}$, whilst variability in the final counts was obtained. Table 1 shows the ranges of the final counts of all the tested strains after exposure to low $\mathrm{pH}$ for 3 h, whereas Fig. 3 shows the viable counts of the most resistant $\mathrm{LAB}$ strains (final counts $>8 \log \mathrm{CFU} / \mathrm{mL}$ ) after $0,0.5,1,2$, and $3 \mathrm{~h}$ incubation in $\mathrm{pH} 2.5$. Overall, 3 strains showed very high resistance to low $\mathrm{pH}$ (LCB26, LCB17 and LCM07) with final populations exceeding $8 \log \mathrm{CFU} / \mathrm{mL}$, whereas 6 strains showed high resistance to low $\mathrm{pH}$ ( 6 and $8 \log \mathrm{CFU} / \mathrm{mL}$ ).

These results are in agreement with those obtained from previous studies, where Lactobacillus strains of food, human or animal origin, were able to retain their viability when exposed to $\mathrm{pH}$ values of 2.5 and 4.0 [25, 50-54]. 


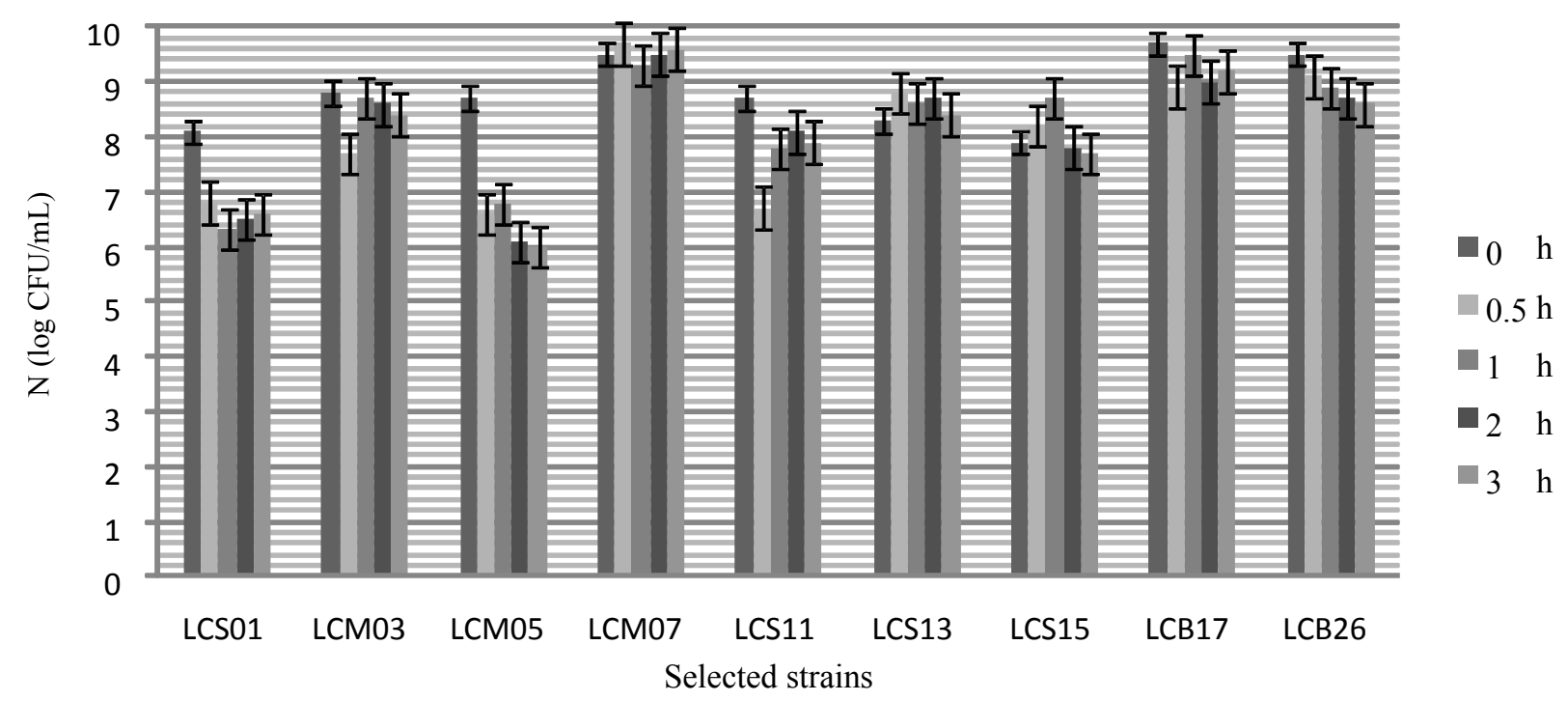

Fig. 3 Resistance for low pH of the selected strains (LCS01: Streptococcus salivarius subsp. thermophilus; LCM03: Leuconostoc lactis; LCM05: Lactococcus lactis subsp. lactis; LCM07: Lactococcus lactis subsp. cremoris; LCS11: Lactococcus lactis biovar. diacetylactis; LCS13: Leuconostoc lactis; LCS15: Lactococcus lactis biovar. diacetylactis; LCB17: Lactobacillus casei subsp. casei; LCB26: Lactobacillus casei subsp. rhamnosus).

Table 3 Tolerance of LAB strains at different bile concentrations for $4 \mathrm{~h}$ of incubation.

\begin{tabular}{llllllllll}
\hline $\begin{array}{l}\text { Bile } \\
\text { salt } \\
(\%)\end{array}$ & \multicolumn{10}{c}{ LCS01 } & LCM03 & LCM05 & LCM07 & LCS11 & LCS13 & LCS15 & LCB17 & LCB26 \\
\cline { 2 - 10 } 0 & $6.50 \pm 0.10$ & $7.12 \pm 0.02$ & $7.18 \pm 0.02$ & $7.33 \pm 0.06$ & $6.90 \pm 0.11$ & $6.50 \pm 0.10$ & $7.44 \pm 0.03$ & $7.02 \pm 0.07$ & $7.50 \pm 0.10$ \\
0.5 & $6.48 \pm 0.08$ & $7.04 \pm 0.14$ & $7.02 \pm 0.02$ & $7.12 \pm 0.05$ & $6.81 \pm 0.04$ & $6.48 \pm 0.08$ & $7.28 \pm 0.07$ & $7.01 \pm 0.06$ & $7.48 \pm 0.03$ \\
1 & $5.89 \pm 0.12$ & $5.14 \pm 0.06$ & $7.01 \pm 0.04$ & $7.09 \pm 0.16$ & $5.98 \pm 0.07$ & $5.89 \pm 0.12$ & $7.02 \pm 0.11$ & $7.01 \pm 0.12$ & $7.29 \pm 0.02$ \\
1.5 & $5.77 \pm 0.09$ & $3.37 \pm 0.29$ & $7.07 \pm 0.06$ & $6.87 \pm 0.11$ & $5.93 \pm 0.03$ & $3.77 \pm 0.09$ & $5.27 \pm 0.12$ & $6.79 \pm 0.04$ & $7.17 \pm 0.05$ \\
\hline
\end{tabular}

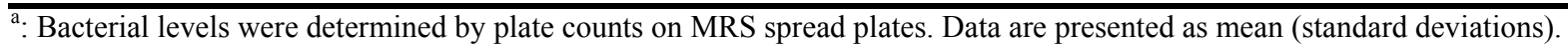

Several assays in vitro have been made to select acid resistant strains by using exposure to $\mathrm{pH}$-adjusted PBS [50, 55], incubation in gastric contents [56] and use of a dynamic model of the stomach [57].

Conway et al. [43] found survival of lactobacilli to be slightly lower when PBS was used rather than gastric juice, because components in the gastric juice could have some protective effect on the bacterial cell. They suggested the use of PBS at the desired $\mathrm{pH}$ to screen strains for their ability to maintain viability in vivo when exposed to gastric juice. Moreover, the probiotic strains could be buffered by food or other carrier matrix molecules following consumption and are thus not likely to be exposed to the $\mathrm{pH}$ of the stomach [58].

3.6.2 Resistance to Bile Salts and Bile salts Hydrolysis Most of the BAL isolates were able to grow in media added with $0.5 \%, 1 \%$ and $1.5 \%$ bile and only 2 were sensitive to the three concentrations of bile evaluated. While the bacilli were able to resist $1.5 \%$ bile concentration, Leuconostocs present a sensibility for this highest concentration, as shown in Table 3 .

The majority of tested strains were found to be resistant to bile salts even after $4 \mathrm{~h}$ of exposure retaining their viability with negligible reduction in viable counts. Only 2 LAB strains (LCM03 and LCS11) demonstrated approximately $3 \log$ reduction after exposure to highest bile salts concentration. Regarding bile salt hydrolysis, 12 strains exhibited partial bile salt hydrolase activity, recorded as differentiated colony morphology on TDCAMRS agar in comparison with the control MRS agar plates. These were the 2 lactobacilli (LCB17 and LCB26) strains. 
Bile plays a fundamental role in specific [57] and non-specific [59] defense mechanism of the gut and the magnitude of its inhibitory effect is determined primarily by the bile salts concentration [60]. Therefore, bile tolerance is considered as an important characteristic of Lactobacillus strains, which enables them to survive, grow, and exert their action in gastrointestinal transit. According to Sanders et al. [61], Lactobacillus strains which could grow and metabolize in normal physical bile concentration could survive in gastrointestinal transit. The resistance to bile salt of some strains was related also to the activity of bile salt hydrolase which can hydrolyze combined bile salt and thus reduce their toxic and side effects. In addition, Gänzle et al. [62] and Du Toit et al. [51] proposed that some components of food could protect and promote the resistance of strain to bile salt.

Bile salt hydrolysis has been correlated to cholesterol lowering [63, 64]. One hypothesis proposes that the cholesterol lowering property of Lactobacillus is due to incorporation of cholesterol into the cellular membranes of bacteria from the medium during its growth period [65]. The main mechanism however is linked to the bile salt hydrolase activity of the cells [66]. Indeed some strains of LAB secrete bile salt hydrolase enzyme, which hydrolyses conjugated bile acids to release de-conjugated bile acids and amino acids $[63,67,68]$. When these salts are secreted from the gastrointestinal tract, the demand for cholesterol is increased, which in turn lowers cholesterol levels $[69,70]$. On the other hand, it is yet not completely clear whether BSH activity is a desirable property for probiotics, since large amounts of de-conjugated bile salts may have undesirable effects for the human host [71, 72]. However, current research data strongly suggest that microbial BSH function in the detoxification of bile salts increases the intestinal survival and persistence of producing strains, which in turn increases the overall beneficial effects associated with the strain [49, 63]. Moreover, the bacterial genera that would most likely be used as probiotics (bifidobacteria and lactobacilli) are not capable of dehydroxylating de-conjugated bile salts [73-75], and thus the majority of the breakdown products of BSH activity by a probiotic strain may be precipitated and excreted in feces $[76,77]$.

\section{Conclusion}

Based on this study, it can be concluded that the Algerian goat's milk contains a variety of lactic acid bacteria display a significant antibacterial activity against pathogenic bacteria. The isolated strains show a good tolerance to gastrointestinal tract conditions and they can be exploited as a promising potential probiotics.

\section{Acknowledgments}

The authors thank Dr. Fatiha Dalache for their support throughout the period of performance of this work.

\section{References}

[1] Agricultural Statistics, 1990-2009, Series D areas and Production, National Center for Statistics, Ministry of Agriculture Algeria, 2009, pp. 22-23.

[2] J. Fontecha, C. Pelaez, M. Juarez, T. Requena, C. Gomez, Iochemical and microbiological characteristics of artisanal hard goat's milk cheese, Journal of Dairy Science 73 (1990) 1150-1157.

[3] T. Requena, M.A. De la Fuente, P. Fernandez de Palencia, M. Juarez, C. Pelaez, Evaluation of a specific starter for the production of semi-hard goat's milk cheese, Lait 72 (1992) 437-448.

[4] C. Olarte, S. Sanz, E. Gonzales-Fandos, P. Torre, The effect of a commercial starter culture addition on the ripening of an artisanal goat's milk cheese (Cameros cheese), Journal of Applied Microbiology 88 (2000) 421-429.

[5] I. Sanchez, S. Sesena, J.M. Poveda, L. Cabezas, L. Palop, Phenotypic and genotypic characterization of lactobacilli isolated from Spanish goat cheeses, International Journal of Food Microbiology 102 (2005) 355-362.

[6] L. Tserovska, S. Stefanova, T. Yordanova, Identification of lactic acid bacteria isolated from Katyk, goat's milk and cheese, Journal of Culture Collection 3 (2002) 48-52.

[7] A. Badis, D. Guetarni, B. Moussa Boudjemaa, D.E. 


\section{Characterization of Antibacterial Activity and Potential as Probiotic of Lactic Acid Bacteria Isolated from Goat's Milk in Algeria}

Henni, M. Kihal, Identification and technological properties of lactic acid bacteria isolated from raw goat milk of four Algerian races, Food Microbiology 21 (2004) 579-588.

[8] M.A. Daeschel, Antimicrobial substances from lactic acid bacteria for use as food preservatives, Food Technology 43 (1989) 164-166.

[9] J. Cleveland, T.J. Montville, I.F. Nes, M.L. Chikindas, Bacteriocins: Safe, natural antimicrobials for food preservation, International Journal of Food Microbiology 71 (2001) 11-20.

[10] L.J. Fooks, R. Fuller, G.R. Gibson, Prebiotics, probiotics and human gut microbiology, International Dairy Journal 9 (1999) 53-61.

[11] E. Tsakalidou, Probiotic potential of Lactobacillus strains isolated from dairy products, International Dairy Journal 16 (3) (2006) 189-199.

[12] L.E. Morrow, V. Gogineni, M.A. Malesker, Probiotics in the intensive care unit, Nutrition Clinical Practice 27 (2) (2012) 235-241.

[13] U. Schillinger, F.K. Lucke, Antibacterial activity of Lactobacillus sake isolated from meat, Applied and Environmental Microbiology 55 (1989) 1901-1906.

[14] B. Aslim, Z.N. Yuksekdag, E. Sarikaya, Y. Beyatli, Determination of the bacteriocin-like substances produced by some lactic acid bacteria isolated from Turkish dairy products, LWT Food Science and Technology 38 (6) (2005) 691-694.

[15] E. Papamaloni, N. Tzanetakis, E.L. Tzanetaki, P. Kotzekidou, Characterization of lactic acid bacteria isolated from a Greek dry-fermented sausage in respect of their technological and probiotic properties, Meat Science 65 (2) (2003) 859-867.

[16] W.F. Harrigan, M.E. McCance, Laboratory Methods in Food and Dairy Microbiology, 2nd ed., Academic Press, London, 1976, pp. 320-321.

[17] M.E. Sharpe, Identification of the lactic acid bacteria, in: F.A. Skinner, D.W. Lovelock (Eds.), Identification Methods for Microbiologist, Academic Press, London, 1979, pp. 233-259.

[18] O. Kandler, N. Weiss, Regular, non-spore-forming Gram positive rods, in: P.H.A. Sneath, N. Mair, M.E. Sharpe, J.G. Holt (Eds.), Bergey's Manual of Systematic Bacteriology, Williams \& Wilkins, Baltimore, Vol. 2, 1986, pp. 1208-1234.

[19] K.H. Schleifer, R. Kilpper-Balz, Molecularand chemotaxonomic approaches to the classification of streptococci, enterococci and lactococci: A review, Systematic Applied Microbiology 10 (1987) 1-19.

[20] R.R. Facklam, M.D. Collins, Identification of Enterococcus species isolated from human infections by a conventional testscheme, Journal of Clinical
Microbiology 27 (1989) 731-734.

[21] M.C. Curk, J.C. Hubert, F. Bringel, Lactobacillus paraplantarum sp. nov., a new species related to Lactobacillus paraplantarum, International Journal of Systematic Bacteriology 46 (1996) 595-598.

[22] W.P. Charteris, P.M. Kelly, L. Morelli, J.K. Collins, Quality control Lactobacillus isolates foruse with the API $50 \mathrm{CH}$ and API ZYM systems at $37{ }^{\circ} \mathrm{C}$, Journal of Basic Microbiology 41 (2001) 241-251.

[23] G. Klein, International Committee of Systematic Bacteriology, subcommittee on the taxonomy of Bifidobacterium, Lactobacillus and related organisms, Minutes of the meeting, International Journal of Systematic Evolution Microbiology 51 (2001) 259-261.

[24] S. Kastner, V. Perreten, H. Bleuler, G. Hugenschmidt, C. Lacroix, L. Meile, Antibiotic susceptibility patterns and resistance genes of starter cultures and probiotic bacteria used in food, Systematic Applied Microbiology 29 (2006) 145-155.

[25] P.A. Maragkoudakis, G. Zoumpopoulou, C. Miaris, G. Kalantzopoulos, B. Pot, E. Tsakalidou, Probiotic potential of Lactobacillus strains isolated from dairy products, International Dairy Journal 16 (2006) 189-199.

[26] G. Zoumpopoulou, B. Foligne, K. Christodoulou, C. Grangette, B. Pot, E. Tsakalidou, Lactobacillus fermentum ACA-DC 179 displays probiotic potential in vitro and protects against TNBS-induced colitis and Salmonella infection in murine models, International Journal of Food Microbiology 121 (2008) 18-26.

[27] B. Ray, W.E. Sandine, Acetic, propionic, and lactic acids of starter culture bacteria as Biopreservatives, in: B. Ray, M. Daeschel (Eds.), Food Biopreservatives of Microbial Origin, Boca Raton, CRC Press, Fla, 1992, pp. 103-136.

[28] H. Nikaido, Outer membrane, in: F.C. Neidhardt (Ed.), Escherichia coli and Salmonella: Cellular and Molecular Biology, American Society for Microbiology, Washington, D.C, 2nd ed., 1, 1996, pp. 29-47.

[29] I.M. Helander, Y. Kato Kilpelainen, I. Kostiainen, R. Lindner, B. Nummila, K. Sugiyama, et al., Characterization of lipopolysaccharides of polymyxin-resistant and polymyxin-sensitive Klebsiella pneumonia $\mathrm{O}_{3}$, European Journal of Biochemistry 237 (1996) 272-278.

[30] L.A. Roth, D. Keenan, Acid injury of Escherichia coli, Canadian Journal of Microbiology 17 (8) (1971) 1005-1008.

[31] K.S. Przybylski, L.D. Witter, Injury and recovery of Escherichia coli after sublethal acidification, Applied and Environmental Microbiology 37 (2) (1979) 261-265.

[32] S. Salminen, M.A. Deighton, Y. Benno, S.L. Gorbach, Lactic acid bacteria in health and disease, in: S. Salminen, A. vonWright (Eds.), Lactic Acid Bacteria: Microbiology 
and Functional Aspects, Marcel Dekker, Inc., New York, 1998, pp. 211-253.

[33] H.L. Alakomi, E. Skyttä, M. Saarela, T. Mattila-Sandholm, K. Latva-Kala, I. Helander, Lactic acid permeabilizes Gram-negative bacteria by disrupting the outer membrane, Applied and Environmental Microbiology 66 (5) (2000) 2001-2005.

[34] A. Savadogo, C.A.T. Ouattara, I.H.N. Bassole, A.S. Traore, Antimicrobial activities of lactic acid bacteria strains isolated from Burkina faso fermented milk, Pakistan Journal of Nutrition 3 (3) (2004) 174-179.

[35] S.E. Lindgren, W.J. Dobrogosz, Antagonistic activities of lactic acid bacteria in food and feed fermentations, FEMS Microbiology Reviews 7 (1990) 149-163.

[36] S. Condon, Responses of lactic acid bacteria to oxygen, FEMS Microbiology Letters 46 (3) (1987) 269-280.

[37] S. Kong, A.J. Davison, The role of interactions between $\mathrm{O}_{2}, \mathrm{H}_{2}, \mathrm{OH}, \mathrm{e}^{-}$and $\mathrm{O}_{2}^{-}$in free radical damage to biological systems, Archives of Biochemistry and Biophysics 204 (1) (1980) 18-29.

[38] S. Ammor, G. Tauveron, E. Dofour, I. Chevallier, Antibacterial activity of lactic acid bacteria against spoilage and pathogenic bacteria isolated from the same meat small-scale facility: 1. Screening and characterization of the antibacterial compounds, Food Control 17 (6) (2006) 454-461.

[39] S. Ammor, C. Rachman, S. Chaillou, H. Pre'vost, X. Dousset, M. Zagorec, et al., Phenotypic and genotypic identification of lactic acid bacteria isolated from a small-scale facility producing traditional dry sausages, Food Microbiology 22 (2005) 373-382.

[40] V. Carolissen-Mckay, G. Arendse, J.W. Mastings, PuriWcation of bacteriocins of lactic acid bacteria: Problems and pointers, International Journal of Food Microbiology 34 (1997) 1-16.

[41] H. Daba, C. Lacroix, J. Huang, R.E. Simard, In Xuence of growth conditions on production and activity of mesenterocine 5 by a strain of Leuconostoc mesenteroides, Applied Microbiology and Biotechnology 39 (1993) 166-173.

[42] E. Parente, A. Ricciardi, Production, recovery and purifications of bacteriocins from lactic acid bacteria, Applied Microbiology and Biotechnology 52 (1999) 628-638.

[43] J.R. Tagg, A.S. Dajani, L.W. Wannamaker, Bacteriocins of Gram-positive bacteria, Bacteriological Reviews 40 (1976) $722-726$.

[44] A.K. Bhunia, M.C. Jonson, B. Ray, N. Kalchayanand, Mode of action of pediocin AcH from Pediococcus acidilacticion sensitive bacterial strains, Journal of Applied Bacteriology 70 (1991) 25-30.

[45] M. Gänzle, S. Weber, W. Hammes, Effect of ecological factors on the inhibitory spectrum and activity of bacteriocins, International Journal of Food Microbiology 46 (1999a) 207-217.

[46] W.H. Holzapfel, P. Haberer, J. Snel, V. Schillinger, J. Huisin't Veld, Overview of gut flora and robiotics, International Journal of Food Microbiology 41 (1998) 85-101.

[47] T.R. Klaenhammer, M.J. Kullen, Selection and design of probiotics, International Journal of Food Microbiology 50 (1999) 45-57.

[48] P.D. Cotter, C. Hill, Surviving the acid test: Responses of Gram-positive bacteria to low $\mathrm{pH}$, Microbiology and Molecular Biology Reviews 67 (2003) 429-453.

[49] M. Begley, G.G. Gahan, C. Hill, The interaction between bacteria and bile, FEMS Microbiology Reviews 29 (2005) 625-651.

[50] P.L. Conway, S.L. Gorbach, B.R. Goldin, Survival of lactic acid bacteria in the human stomach and adhesion to intestinal cells, Journal of Dairy Sciences 70 (1) (1987) $1-12$.

[51] M. Du Toit, C.M. Franz, L.M. Dicks, U. Schillinger, P. Haberer, B. Warlies, et al., Characterisation and selection of probiotic lactobacilli for a preliminary mini pig feeding trial and their effect on serum cholestrerol levels, faeces $\mathrm{pH}$ and faeces moisture content, International Journal of Food Microbiology 40 (1998) 93-104.

[52] C.N. Jacobsen, V. Rosenfeldt Nielsen, A.E. Hayford, P.L. Moller, K.F. Michaelsen, A. Paerregaard, et al., Screening of probiotic activities of forty-seven strains of Lactobacillus spp. by in vitro techniques and evaluation of the colonization ability of five selected strains in humans, Applied Environment Microbiology 65 (1999) 4949-4956.

[53] C. Dunne, L. Murphy, S. Flyin, L. O’Mahony, S. O'Halloran, M. Feeney, et al., Probiotics: From myth to reality, demonstration of functionality in animal models of disease and in human clinical trials, Antonie van Leeuwenhoek 76 (1999) 279-292.

[54] V. Xanthopoulos, E. Litopoulou-Tzanetaki, N. Tzanetakis, Characterization of Lactobacillus isolates from infant faeces as dietary adjuncts, Food Microbiology 17 (2) (2000) 205-215.

[55] J.H. Park, J.I. Um, B.J. Lee, J.S. Goh, S.Y Park, W.S. Kim, et al., Encapsulated Bifidobacterium bifidum potentiates intestinal IgA production, Cellular Immunology 219 (2002) 22-27.

[56] A. Fernández, J.L. Ruiz-Barba, Optimization of bacteriocin production by batch fermentation of Lactobacillus plantarum LPCO10, Applied Environmental Microbiology 68 (2002) 4465-4471.

[57] P. Marteau, M. Minekus, R. Havenaar, J.H.J. Huis In't Veld, Survival of lactic acid bacteria in a dynamic model 


\section{Characterization of Antibacterial Activity and Potential as Probiotic of Lactic Acid Bacteria Isolated from Goat's Milk in Algeria}

of the stomach and small intestine: Validation and the effects of bile, Journal of Dairy Sciences 80 (6) (1997) 1031-1037.

[58] J. Prasad, H. Gill, J. Smart, P.K. Gopal, Selection and characterisation of Lactobacillus and Bifidobacterium strains for use as probiotics, International Dairy Journal 8 (12) (1998) 993-1002.

[59] T. Kalambaheti, G.N. Cooper, G.D.F. Jackson, Role of bile in non-specific defence mechanisms of the gut, Gut 35 (1994) 1047-1052.

[60] C. Dunne, L. O’Mahony, L. Murphy, G. Thornton, D. Morrissey, S. O'Halloran, et al., In vitro selection criteria for probiotic bacteria of human origin: Correlation with in vivo findings, Journal of Clinical Nutrition 73 (2) (2001) 386-392.

[61] M.E. Sanders, D.C. Walker, K.M. Walker, K. Aoyama, T.R. Klaenhammer, Performance of commercial cultures in fluid milk applications, Journal of Dairy Sciences 79 (6) (1996) 943-955.

[62] M.G. Gänzle, C. Hertel, J.M. van der Vossen, W.P. Hammes, Effect of bacteriocin-producing lactobacilli on the survival of Escherichia coli and Listeria in a dynamic model of the stomach and the small intestine, International Journal of Food Microbiology 48 (1) (1999b) 21-35.

[63] M. Begley, G.G. Gahan, C. Hill, Bile salt hydrolase activity in probiotics, Applied Environnement Microbiology 72 (2006) 1729-1738.

[64] M.T. Liong, N.P. Shah, Acid and bile tolerance and cholesterol removal ability of Lactobacilli strains, Journal of Dairy Science 88 (2005) 55-66.

[65] S. Gilliland, T. Staley, L. Bush, Importance of bile tolerance of Lactobacillus acidophilus used as dietary adjunct, Journal of Dairy Science 67 (1984) 3045-3051.

[66] M.P. Taranto, F. Sesma, A. Pesce de Ruiz Holgado, G.F. de Valdez, Bile salts hydrolase plays a key role on cholesterol removal by Lactobacillus, Biotechnology Letters 19 (9) (1997) 845-847.

[67] N. Sridevi, P. Vishwe, A. Prabhune, Hypocholesteremic effect of bile salt hydrolase from Lactobacillus buchneri ATCC 4005, Food Research International 42 (2009)
516-520.

[68] C.M. Franz, M. Huch, H. Abriouel, W. Holzapfel, A. Gálvez, Enterococci as probiotics and their implications in food safety, International Journal of Food Microbiology 151 (2) (2011) 125-140.

[69] B.Z. De Rodas, S.E. Gilliland, C.V. Maxwell, Hypocholesterolemic action of Lactobacillus acidophilus ATCC 43121 and calcium in swine with hypocholesterolemia induced by diet, Journal of Dairy Science 79 (1996) 2121-2128.

[70] F.M. Driessen, R. De Boer, Fermented milks with selected intestinal bacteria: A healthy trend in new products, Netherland Milk Dairy Journal 43(1989) 367-382.

[71] F. Berr, G.A. Kullak-Ublick, G. Paumgartner, W. Munzing, P.B. Hylemon, W.P. Charteris, et al., Effect of conjugated bile salts on antibiotic susceptibility of bile salt-tolerant Lactobacillus and Bifidobacterium isolates, Journal of Food Protection 63 (1996) 1369-1376.

[72] A. Mamianett, D. Garrido, C.N. Carducci, M.C. Vescina, Fecal bile acid excretion pattern profile in gallstone patients, Medicina 59 (1999) 269-273.

[73] Y.T. Ahn, G.B. Kim, K.S. Lim, Y.J. Baek, H.U. Kim, Deconjugation of bile salts by Lactobacillus acidophilus isolates, International Dairy Journal 13 (4) (2003) 303-311.

[74] S.E. Gilliland, M.L. Speck, Use of the Ylinitek system for characterizing lactobacilli, Applied Environment Microbiology 33 (1977) 1289-1292.

[75] T. Takahashi, M. Morotomi, Absence of cholic acid 7a-dehydroxylase activity in the strains of Lactobacillus and Bifidobacterium, Journal of Dairy Sciences 77 (1994) 3275-3286.

[76] L.A. Thomas, M.J. Veysey, T. Bathgate, A. King, G. French, N.C. Smeeton, et al., Mechanism for the transit-induced increase in colonic deoxycholic acid formation in cholesterol cholelithiasis, Gastroenterology 199 (2000) 806-815.

[77] M.J. Veysey, L.A. Thomas, A.I. Mallet, P.J. Jenkins, G.M. Besser, G.M. Murphy, et al., Colonic transit influences deoxycholic acid kinetics, Gastroenterology 121 (2001) 812-822. 